\title{
Poliomyelitis and its Health Consequences in the Whole Community in Kabul City, Afghanistan
}

Article by Mohammad Aqa Stanikzai

Publich Health, Texila American University

E-mail: dr_stanikzai0093@yahoo.com

\begin{abstract}
Poliomyelitis is an acute infection caused by a poliovirus. It's a nonspecific minor illness called (abortive poliomyelitis) and, less often, flaccid weakness of various muscle groups called (paralytic poliomyelitis). This is a disease of childhood and can not be happened after five years of age, can affect both sex in all country including Afghanistan. According to the world Health Organiztion (WHO) report for 2015 the polio virus has totally been eliminated from the whole world except three countries, (Afghanistnan, Pakistan, and Nigeria).
\end{abstract}

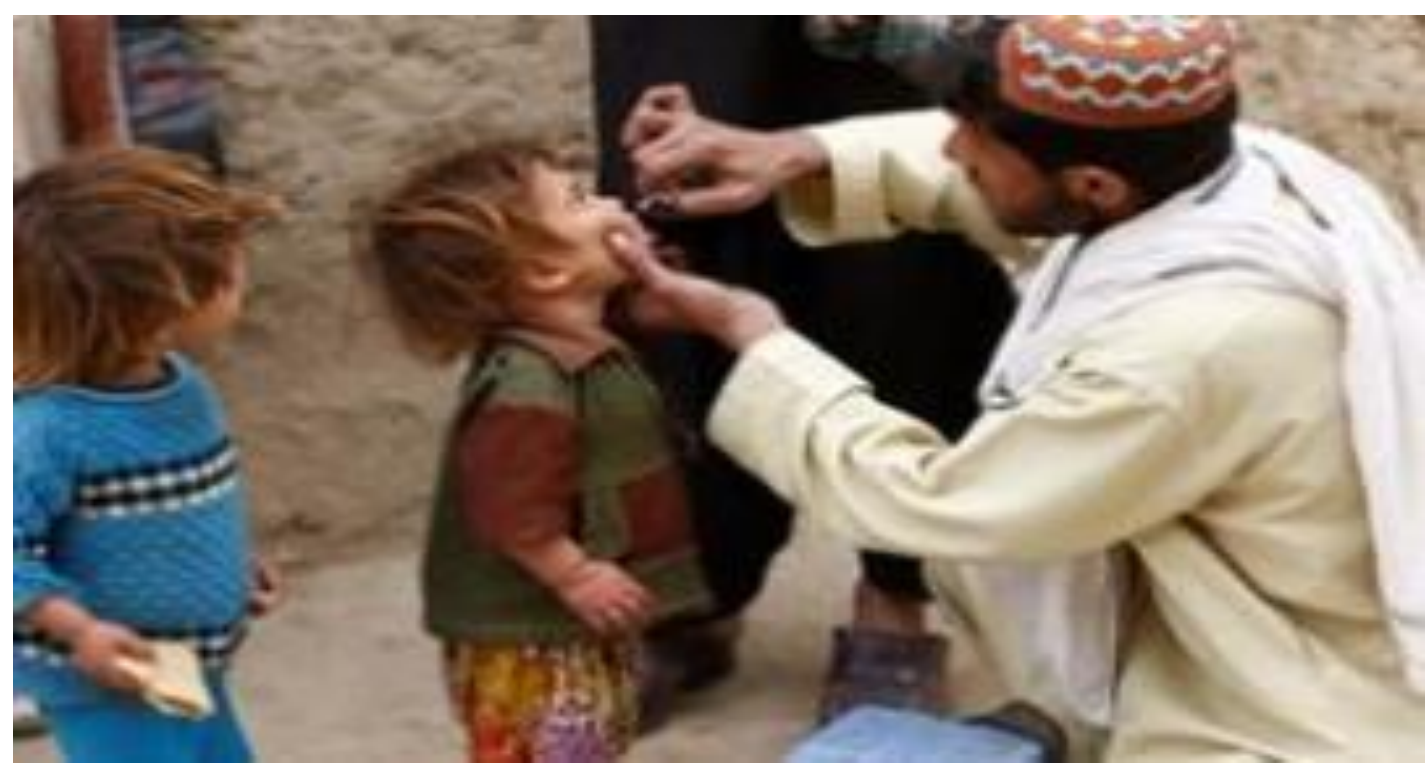

A child receives two drops of the oral polio vaccine during a National Immunization Days campaign in Kandahar province

The above banner shows the commitment of the Ministry of public health, the efforts/compaign launched to eradicate the polio and having to carry out the public anti polio massive compaign and raising awareness among the people in the country.

\section{Acronymes}

$\begin{array}{ll}\text { UNICEF } & \text { United Nations International Children's Emergency Fund } \\ \text { MoPH } & \text { Ministry of Public Health } \\ \text { MCN } & \text { Ministry of Counter Norcotics } \\ \text { CDC } & \text { Center for Disease Control } \\ \text { Govt Af } & \text { Government of Afghanistan } \\ \text { NGO } & \text { Non goernmental Organization } \\ \text { WHO } & \text { World Health Organization } \\ \text { PDs } & \text { Plio Drops } \\ \text { NIH } & \text { National Institute of Health } \\ \text { NCVIA } & \text { National Childhood Injury Act }\end{array}$




\section{Introduction}

Plio is an infectious disease especially of young children population that is caused by the poliovirus Individuals infected with the poliovirus are often asymptomatic.

In approximately $25 \%$ of cases, polio presents as a mild to moderate illness marked by headache, fever, sore throat, vomiting, diarrhea, and fatigue. Polio affects the central nervous system only infrequently with inflammation and sometimes destruction of the motor neurons in the gray matter of the spinal cord and brain stem. Central nervous system involvement results in temporary or permanent muscle weakness or motor paralysis especially of the limbs and typically the legs. Polio may become life-threatening when paralysis affects the muscles involved in breathing and swallowing. Polio is endemic in only four countries: Pakistan, Afghanistan and regions of Nigeria and India, according to the ministry of health of afghainstan, it has committed to eliminate this virus from the whole parts of Afghanistan by 2018, but due to insecurity, displacement and migration between bordering Pakistan and Afghanistan and the insecure places in the vicinity of both countries still the virus has been existed in both countries despites of its strong commitments of both sides.

\section{Objectives}

The objective of this project is to bring up the applicable, consteffective innovative ideas to eliminate the polio virus in the whole four afghan provincial regions and evaluate the impact of polio in our country and its negative consequesnce which badly damaged the Afghan populations particularly below the age of under five in the urban and rural areas of the country.

\section{Methodology}

- A rapid assessment was conducted in term of qualitative and quantitative study.

- Secondary data collection and review.

- Direct observation from polio centers.

- Interviews with some staff for the secondary data collection.

\section{What is poliomyelitis: (medical definition)}

Poliomyelitis, isalso called polio or infantile paralysis, is a highly infectious viral disease that may attack the centralnervous system and is characterized by symptoms that range from a mild nonparalytic infection to total paralysis in amatter of hours. As the media are not technical in such issue and have no enough scientifical information regarding the Polio, therefore the most information was provided from the public which is not as effecients as as its, in addition to the media can play a vital role for the eradication and polio prevention based on the launching of the round table and radio broadcasting with the direct help of the experts and medical personnel which can lead to have the positive impact on the people and enhance their knowlwdge how to technically tackle the issue in a very modernized and cost effective way.

\section{What is poliomyelitis (Defination from the community aspect)}

Polio or poliomyelitis is an infectious diseases, which is mostly prevailed among children under five and mostly affecting the vulnerable and weak immuned children whom their manpower (immunity) is very low and expsed to infections. Polio has not been identified as a medical problem among the community and does not have any specific remedy and therapy. Such cased commonly been treated by the Mullahs, shaikh and elders of the community to assist these patients in a traditional way. Which mostly does not proven its effectiveness nor the disease were reversed, But still the main misconception is goining on among the public for the dislocation of the joints, It is needed that the individual faced the problem with dislocation to consult an orthopaedist to fix the bone problem or any dislocations has been happened, BUT unfortunately still they are not believed to go the orthopeadist to fixt their dilocations of any part of the body and still this malpractices/ misconception is going on and they are going to the traditional and illiterate person to fix their dislocation and using the home made medicince. 


\section{What is poliomyelitis (definition from media and broadcasting prospective views)}

It's a medical problem, which results based on the immune compromised clients and mostly been talking from the medial point of view and mostly on the day of polio, some channels are broadcasting the polio communication virus is soley contracted and its communication at different ways.

In Afghanistan we have more then $70 \mathrm{TV}$ chenneals at different location and states / provinces of afgahanistan, and more then 120 daily news papers which is mostly broadcasing and primarily focusing the capital Kabul and the four major regions (mazar, Herat, Jalalabad and Kabul) of afghanistan, most all these medias are soponsored by the different exernal donors and some of them are self-sponsored or private channel. Among these channels particiulaty some of radios and TVs are pertained to the excommanders and Jehadi leaders, which mostly broadcasting their pro party and interesting topics during the broadcasting hourse.

Therefore Based on the various definition and briefings, we also have a big massive compaing to the awareness and elimination of polio, through various TV chennels, Radio and printed media (articles, magazine, leaflets and bruchures in the country, as I know since Afghanistan has started its compaign against polio contract and communication in the country, most social society organizations pertaining to the polio eradication and elimination had its vital rule in providing the informative leaflelts, messages and sound medias whcich proved effective.

In my country (Afghanistan) we have a massive compaings against the polio eradication and providing polio drops to the children under five years, we mostly heard from the NGOS working in the filed of health, social community workers and sometimes from the IMAM of Masjid (Mullahs or preachers), to convey the anti-polio messages and information from the Islamic point of view, as 99.9 percent of afghans are Muslim therefore the Imam preach has the vital and tremendous impact on the society and on larger proportion of the people in the remotest and urban areas of the country.

\section{Polio from the Ministry of public health point of view in the country}

It's a viral disease which lead the under-five vulneralbes kids to a paralytic status and mostly in a permanent handicapping, therefore, Since long time ago the Ministry of public Health of Afghanistan has began the polio awareness program and polio eradiction in the county and mostly been alligned with some funding agencies providing and procuring the polio drops to the government of the Afghganistan, such donors whom provided polio drops to Afghanistan are currently been UNICIEF, EMRO and WHO, all these actors actively serves and provides the country with the funding and procuring the drops to assist the government of Afghanistan and to go along the clients to re- affirm their commitment for the eradication and elimination of polio virus in the country.

Despites above actors, we have some local actors/bodies and organizations whom they were mostly been active in the ground for any sort of compaign against the polio in the county and supporting the $\mathrm{MOH}$ and speeding up the elimination of the polio-prevalence in the whole country are briefly mentioned below.

1- Social society organizations (funded by its local donation and external donors)

2- Non governmental Organizations (funded by external donors) which mostly working the remotiest and hard access areas in the country.

3- Private clinics which provides polio drops and cooperate with the ministry of health to reach out their goals.

\section{Impact of polio on the individual}

The below factors can contribute to fail the polio program due to the below mentioning points.

- Low awareness among the poullation of all ages (due to low letracey)

- No assistance of the Malik Guzar (community leaders and influential bodies in rural areas)

- No access to the media and news papers in the hard and remote access areas of the country to enhance their level of knowledge and understand about the impact of polio drops to communicate the issue to the rural population.

- No security or big security concern are still available in some regional zone for preventing the health worker to carry out their tasks properly and distribute the polio drops to the children in the villange based health facilities. 
- Life threatening of the health workers, community mobilizers and progaganda against the polio and its prevention program in the remote and border areas of the country (unfortuneatley we have most cases from that areas.

- The main problem is still existed is the therathening of health workers and sometimes their killing during the polio compaign and polio drop in days have the bad experience of our health worker in the some parts of the country and tribal areas.

\section{Burden and impact of polio from economic prospectives}

As I had a quick visit to the clinics and getting the secondary data to understand the whole nature of the disease and its economic burden, I really found the most important aspect of the human live which makes the backbone of the families were the productive life of the individual.

That people who were affected and contracted this virus is really having the unbelievable and miserable conditions which totally make a person inactive and sluggish in its production and leads the income due to its physical handicapping and unemployment to the zero level. And most of the post paralytics patients life were not adapting to the employment situation nor they culturally been adapted to find asuitalbe jobs to run their family. (distorted family income)

It really affects the family and individually economic as a whole, as met some of them now adays they were paralayesed, flaccid lower limbs, beside they are sufferd from the physical inability and routine works they have toughly been faced with big challenges of job placement in the community and the low status of these clients based on their income and community living status as a whole.

In My country most of them have semi- officially been labored with the half wage of the normal people. At the same time they have not been hired in a dignitary and high wages/ranks jobs in the community due to their physical deficits.

The main reason and rational is that they have the perception of the community is that they can not work due to their, physical inability, handicapped status (some of them have lost their lower and upper limbs) and been illiterate due to their marginalization and exclusion from the community.

Therefore, I had a meeting and interview with some of them they were mostly feeling frustration and debilitating due to their marginaliation and depressive moods, But fortunately in the current viable environment of the government of Afghanistan which recently have established a ministry under the name of Ministry of martyers and handicapped to support their family and in some cases if they are capable of physical or professional skills they have been hired based on their professicency and market needs, and the conceren is still with handicapped to be part of the normal system but still it is not happened due to their inability, low literacy rates, and physical debilitating status.

\section{Specilized clinic for polio patients deformities}

Since the polio problem has been emerged and cases have been detected no specialized hospital and clinics were established in such purposes, still the problem has been identified as a big burden to the individual, family and somehow to the ministry of public health in the country, most cases with paralysis and deformity have not been provided special services and still been a problem in the country of poors not the government nor the family can pay for their disability and debilitating status of polio clients.

Still the deformed patients are suffering from the non availability of the specialized clinic in the country.

Based on the world report for the 2015, only 74 cases of wild polio virus (WPV) were identified and detected.

All the cases reported were from the WPV type 1 (WPV1), the only known WPV type still circulating, WPV type 2 has totally been eradicated, and WPV type 3 has not been detected since November 2012 (1). In 2015 in Afghanistan, WPV detection also declined from 2014, and trends observed in 2016 suggest that circulation of the virus is limited to a few localized areas. Despite the progress, there are concerns about the ability of the country's Polio Eradication Initiative (PEI) to meet the goal of interrupting endemic WPV transmission by the end of 2016.

\section{Demographic status of the country}


The population of Afghanistan is around 32 million as of 2015, which includes the 2.7 million Afghan citizens that are residing temporarily in Pakistan and Iran. The nation is composed of a multiethnic and multilingual society, reflecting its location astride historic trade and invasion routes between Central Asia, Southern Asia, and Western Asia. The largest ethnic group among Afghanistan's population is the Pashtuns, followed by Tajiks, Hazaras, Uzbeks, Aimaks, Turkmen, Baloch and others.

As of $201346 \%$ of Afghanistan's population are under 15 years of age and $74 \%$ of the population live in rural areas. The average woman gave birth to five children during her life and $6.8 \%$ of all babies died in child-birth or infancy. Life expectancy in 2013 was 60 years and only $0.1 \%$ of the population between ages 15 and 49 had HIV.

Pashto and Dari (Afghan Persian) are both the official languages of the country. Dari is mostly spoken in the Tajik- and Hazara-dominated areas, while Pashto is spoken mainly in the Pashtun tribal areas south of the Hindu Kush mountains. Uzbek and Turkmen are spoken in parts of the north. Smaller groups in various parts of the country speak about 30 other languages. Multilingualism is common throughout the country, especially in the major cities. Dari is the predominate language spoken in urban areas but language is not necessarily an indicator of an individuals ethnic or group identity since Pashto and Dari are both spoken by nearly all of the country's ethnic groups (Turkmen and Uzbeks generally constituting an exception to this rule).

Islam is the religion of more than 99\% of Afghanistan's citizens. An estimated 80-90\% of the population practice Sunni Islam and belong to the Hanafi Islamic law school, while 7-19\% are Shia; the majority of the Shia follow the Twelver branch, with smaller numbers of Ismailis. The remaining $1 \%$ or less practice other religions such as Sikhism and Hinduism. Excluding urban populations in the principal cities, most People are organized into tribal and other kinship-based groups, who follow their own traditional customs, for instance Pashtuns Pashtunwali. The majority of the country's population lives in rural areas and is involved in agricultural activities.

\section{Interveiw with clinic staff and community influential}

I went to one of the polio drops clinic in kaubl city for collection of secondary data and asking question for the prevalence, quantative and qalitatives progress/changes made for the 2015-16. I checked the registration, meeting with the polio mobilizer team, and had interview with some community elder about the polio cases found and happened during the recent years.

I found an enectodal number of the polio cases and stories from the them based on their knowledge, familiarity with the polio, and in some casese the pre and post polio cases status from them, they mostly were saying that,

(a) since five- six years the knowledge about polio have been enhanced among the general population and particularly among the medical staff.

(b) the polio drops have improved the quality of the life of unders five children as they were regularly taking the drops mostly in the secured location and province of Afghanistan, incontrodactory to the insecrued areas which the reports shows the highest number of cases from that areas.

(c) availability of drops and distribution of polio burchure and articules/ pictorials have assisstaned the people to join the compaing and have and fruitful results.

\section{Below are the Number of the polio cases in endemic countries}

\begin{tabular}{|c|l|l|l|l|}
\hline S/N & Country & Cases 2014 & Cases 2015 & $\begin{array}{l}\text { Cases } \\
2016\end{array}$ \\
\hline 1 & Afghanistan & 28 & 20 & 13 \\
\hline 2 & Pakistan & 309 & 51 & 19 \\
\hline 3 & Nigeria & 6 & 0 & 4 \\
\hline
\end{tabular}

Polio Cases in Afghanistan in last three years

\begin{tabular}{|l|l|l|l|l|}
\hline S/N & Region & \multicolumn{3}{|l|}{ Year } \\
\hline & & $\mathbf{2 0 1 3}$ & $\mathbf{2 0 1 4}$ & $\mathbf{2 0 1 5}$ \\
\hline 1 & Central & 1 & 0 & 0 \\
\hline 2 & East & 12 & 6 & 10 \\
\hline
\end{tabular}


DOI: $10.21522 /$ TIJPH.2013.05.04.Art050

ISSN: $2520-3134$

\begin{tabular}{|l|l|l|l|l|}
\hline 3 & Southeast & 0 & 4 & 0 \\
\hline 4 & South & 1 & 17 & 2 \\
\hline 5 & North & 0 & 0 & 1 \\
\hline 6 & Northeast & 0 & 0 & 0 \\
\hline 7 & West & 0 & 1 & 6 \\
\hline \multicolumn{2}{|l}{ Total number of cases } & $\mathbf{1 4}$ & $\mathbf{2 8}$ & $\mathbf{1 9}$ \\
\hline
\end{tabular}

*Data is as of 25 Feb. 2015

The most recent case: The most recent confirmed case is reported from Chapadar district of Helmand province. The case is a 20-month-old female child with onset of paralysis on 19 November 2015. The case is reported from inaccessible areas.

\section{What is the medical treatment for polio in the country?}

There is no medical treatment that will cure polio disease, once the virus has infected the patient. The key to treatment is early diagnosis and supportive treatments such as bed rest, pain control, good nutrition, and especially physical therapy to prevent deformities from occurring over time and prevention of muscle function loss. Some patients will need extensive support such as breathing assistance and special diets if they cannot swallow or have difficulty swallowing; others may require splints to avoid pain, muscle spasms, and limb deformities.

\section{Is Surgery a Treatment for Polio?}

There is an extensive body of literature that describes the various surgical techniques that have been used to treat polio patients. Most polio patients who undergo surgery have either not had treatment or failed medical treatments and are often in the residual or post-polio syndrome stage (see prognosis section below). Such a discussion is too lengthy to present in this article, but the surgical topics listed below can give readers insight into the long-term complications that may result from paralytic polio and why vaccination that prevents the disease is so important:

- Contracture release surgery

- Muscle transplantation

- Joint stabilization, joint fusion, and joint replacement surgery

- Limb lengthening

- Foot correction surgery

\section{What is the follow-up for polio?}

Follow-up of patients with polio, especially those who develop the paralytic disease is often lifelong and remains the best way to reduce complications and treat the disease symptoms. Depending on the severity of the disease symptoms, follow-up care may range from physical therapy to multiple surgical interventions.

A major reason for follow-up is to monitor the patient for post-polio syndrome. Post-polio syndrome is a condition of increasing muscle weakness, muscle pain, and fatigue that can appear about 15-30 years after recovery from the initial paralytic disease. It may occur in $25 \%-50 \%$ of patients who develop paralytic polio. Treatment of symptoms is fuly supportive such as (rest, braces, and pain control).

\section{Public health prospect of polio virus (history of vaccine safety)}

Vaccines are one of the greatest success stories in public health. Through use of vaccines, we have eradicated smallpox and nearly eliminated wild polio virus. The number of people who experience the devastating effects of preventable infectious diseases like measles, diphtheria, and whooping cough is at an all-time low. To ensure the continued success of vaccines in the United States, it's crucial to make sure that vaccines are safe.

Before vaccines are approved by the Food and Drug Administration (FDA), they are tested extensively by scientists to ensure they are effective and safe. Vaccines are the best defense we have against infectious diseases; however, no vaccine is actually $100 \%$ safe or effective for everyone because each person's body reacts to vaccines differently. 
As infectious diseases become less common, we hear less about the serious consequences of preventable illnesses like diphtheria and tetanus and more about the risks associated with vaccines. It's good to be informed about health choices, but the reality is that Americans have never been healthier than we are today and vaccines have never been safer than they are today. The benefits of vaccines far outweigh the risks. As science continues to advance, we strive to develop safer vaccines and improve delivery to protect ourselves against disease more effectively. This overview focuses on vaccine research, how vaccines are licensed, and how we make sure vaccines are safe.

\section{National childhood vaccine injury act}

During the mid-1970s, there was an increased focus on personal health and more people became concerned about vaccine safety. Several lawsuits were filed against vaccine manufacturers and healthcare providers by people who believed they had been injured by the diphtheria, pertussis, tetanus (DPT) vaccine. Damages were awarded despite the lack of scientific evidence to support vaccine injury claims. As a result of these decisions, liability and prices soared, and several vaccine manufacturers halted production. A vaccine shortage resulted and public health officials became concerned about the return of epidemic disease. To reduce liability and respond to public health concerns, Congress passed the National Childhood Vaccine Injury Act (NCVIA) in 1986.

This act was influential in many ways.

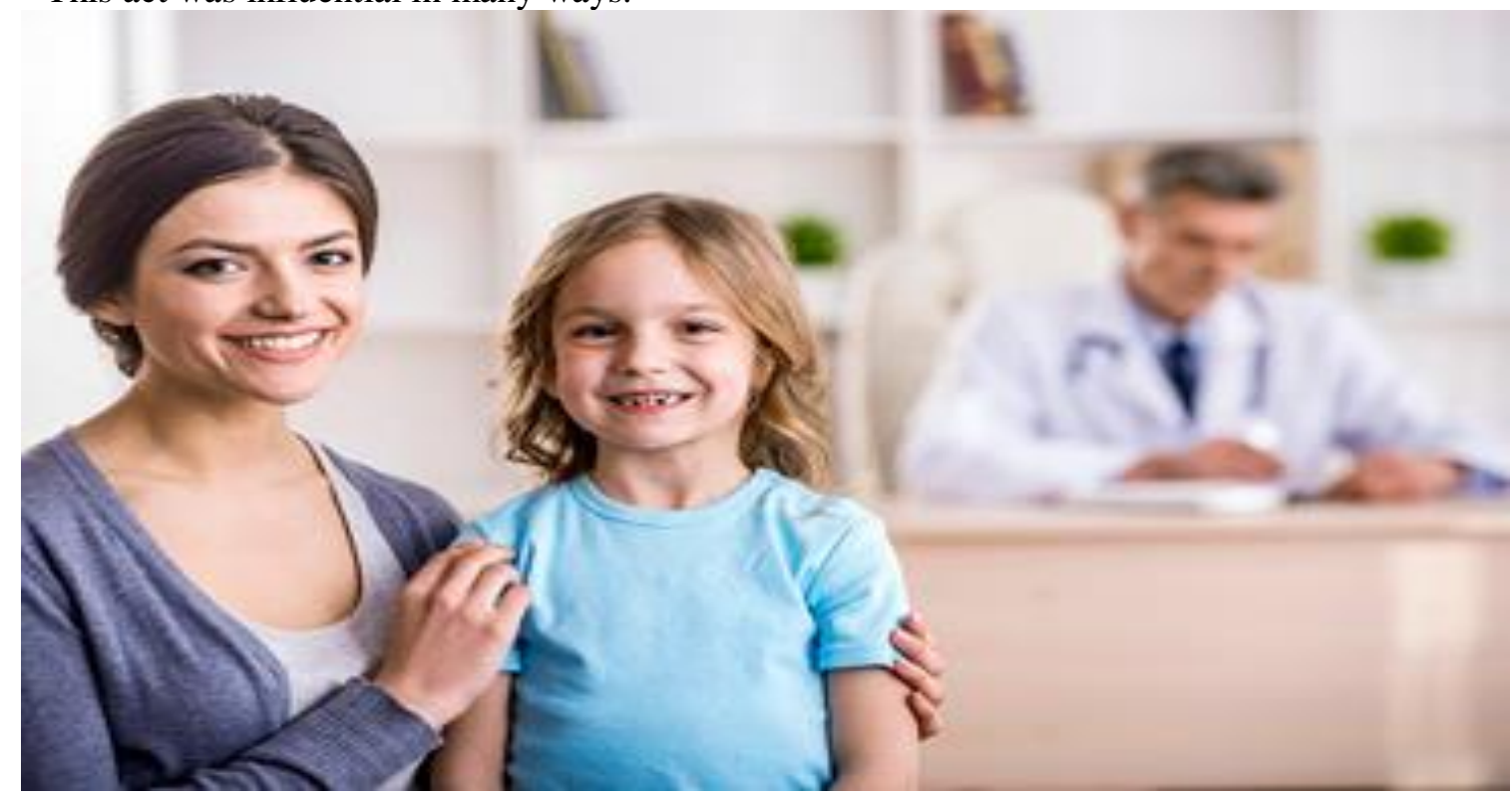

The National Vaccine Program Office (NVPO) was established to coordinate immunization-related activities between all Department of Health and Human Services (DHHS) agencies including the Centers for Disease Control and Prevention (CDC), Food and Drug Administration (FDA), National Institutes of Health (NIH), and the Health Resources and Services Administration (HRSA).

- The NCVIA requires health care providers who administer vaccines to provide a vaccine information statement (VIS) to the person getting the vaccine or his or her guardian. A VIS must be given with every vaccination including each dose in a multi-dose series. Each VIS contains a brief description of the disease as well as the risks and benefits of the vaccine. CDC develops VISs and distributes them to state and local health departments as well as individual providers.

- The NCVIA also requires health care providers to report certain adverse events (health effects occurring after immunization that may or may not be related to the vaccine) following vaccination to the Vaccine Adverse Event Reporting System (VAERS).

- Under the NCVIA, the National Vaccine Injury Compensation Program (NVICP) was created to compensate those injured by vaccines on a "no fault" basis.

- The NCVIA established a committee from the Institute of Medicine (IOM) to review the literature on vaccine reactions. This group concluded that there are limitations in our knowledge of the risks associated with vaccines. The group looked at 76 health problems to see if they were caused by 
vaccines. Of those, 50 (66\%) had no or inadequate research to form a conclusion. Specifically, the IOM identified the following problems:

1. Limited understanding of biological processes that underlie adverse events.

2. Incomplete and inconsistent information from individual reports.

3. Poorly constructed research studies (not enough people enrolled for the period of time).

4. Inadequate systems to track vaccine side effects.

Few experimental studies were published in the medical literature.

Significant progress has been made over the past few years to monitor side effects and conduct research relevant to vaccine safety.

\section{Current delivery and use of vaccines}

National efforts to promote vaccine use among all children began with the appropriation of federal funds for polio vaccination after introduction of the vaccine in 1955. Since then, federal, state, and local governments and public and private health-care providers have collaborated to develop and maintain the vaccine-delivery system in the United States.

Overall, U.S. vaccination coverage is at record high levels. In 1997, coverage among children aged 19-35 months (median age: 27 months) exceeded $90 \%$ for three or more doses of diphtheria and tetanus toxoids and pertussis vaccine (DTP), three or more doses of poliovirus vaccine, three or more doses of Hib vaccine, and one or more doses of measles-containing vaccine. Coverage with four doses of DTP was $81 \%$ and for three doses of hepatitis B vaccine was $84 \%$. Coverage was substantially lower for the recently introduced varicella vaccine $(26 \%)$ and for the combined series of four DTP/three polio/one measles-containing vaccine/three Hib (76\%) (15). Coverage for rotavirus vaccine, licensed in December 1998, has not yet been measured among children aged 19-35 months. Coverage among children aged 5-6 years has exceeded 95\% each school year since 1980 for DTP; polio; and measles, mumps, and rubella vaccines (CDC, unpublished data, 1998).

\section{Future direction}

Vaccines are one of the greatest achievements of biomedical science and public health. Despite remarkable progress, several challenges face the U.S. vaccine-delivery system. The infrastructure of the system must be capable of successfully implementing an increasingly complex vaccination schedule. An estimated 11,000 children are born each day in the United States, each requiring 15-19 doses of vaccine by age 18 months to be protected against 11 childhood diseases. In addition, licensure of new vaccines is anticipated against pneumococcal and meningococcal infections, influenza, parainfluenza, respiratory syncytial virus (RSV), and against chronic diseases (e.g., gastric ulcers, cancer caused by Helicobacter pylori, cervical cancer caused by human papilloma virus, and rheumatic heart disease that occurs as a sequela of group A streptococcal infection). Clinical trials are under way for vaccines to prevent human immunodeficiency virus infection, the cause of acquired immunodeficiency syndrome.

To achieve the full potential of vaccines, parents must recognize vaccines as a means of mobilizing the body's natural defenses and be better prepared to seek vaccinations for their children; health-care providers must be aware of the latest developments and recommendations; vaccine supplies and financing must be made more secure, especially for new vaccines; researchers must address increasingly complex questions about safety, efficacy, and vaccine delivery and pursue new approaches to vaccine administration more aggressively; and information technology to support timely vaccinations must be harnessed more effectively. In addition, the vaccine-delivery system must be extended to new populations of adolescents and adults. Each year, thousands of cases of potentially preventable influenza, pneumococcal disease, and hepatitis B occur in these populations. Many of the new vaccines will be targeted at these age groups. The U.S. vaccine-delivery system must routinely include these populations to optimally prevent disease, disability, and death.

Despite the dramatic declines in vaccine-preventable diseases, such diseases persist, particularly in developing countries. The United States has joined many international partners, including the World Health Organization and Rotary International, in seeking to eradicate polio by the end of 2000. Efforts to accelerate control of measles, which causes approximately one million deaths each year (5), and to expand rubella vaccination programs also are under way around the world. Efforts are needed to expand 
the use of existing vaccines in routine childhood vaccination programs worldwide and to successfully introduce new vaccines as they are developed. Such efforts can benefit the United States and other developed countries by decreasing disease importations from developing countries.

Reported by: National Immunization Program, CDC.

\section{My findings and observations}

As asseseed in my this capstone project the most aspects of the polio disease, and its negative consequences were considered separately, visiting the droping centers and health workers, the over all situation of polio in the country particularly the areas of the high risk and insecure location of the country and detection of such polio cases which lead the person inable and permanatly physically handicapped and unproductive. Finally I found the following factors and evidence behind the contraction of the virus and concurrently the following points can contribute for the prevention of the polio in my counry.

The below Risk factors can not to be ignored if the child has not been vaccinated mostly In undermentiond situation.

- Traveling to an area where polio is common or that has recently experienced an outbreak of the cases.

- Living with or caring for someone who may be shedding poliovirus

- A compromised immune system, such as occurs with HIV infection etc.

- Having had tonsils removed (tonsillectomy) the person may have low body immune system.

- Extreme stress or strenuous physical activity after being exposed to poliovirus, both of which can depress your immune system

In addition I would like to mention the below points which directly affect the elimination program of the polio virus and virtually contribute the prevalence of the issue in some special condition in my country.

- The east part of the country is bordering Pakistan in tribal areas, which is mostly the high insecure part of the country and Afghanistan is suffering very badly in term of clashes, terror attacks, human trafficking etc., and most cases of polio are detected in these areas, according to the WHO 2015 report we have 10 polio casese detected in this area, and no body particulaty the health workers are unable to go for the vaccinaiotn program there, since very long time due to insecured situation and traditional bordering custume.

- In the west part of the country (paktika province) unfortunately we are also having very long distance border with Pakistan, which are the mostly tribal and the inhabitant of the areas is mostly the illiterate people, and no educational inistitute or schools are running there due to the recurrent attack of terrorist crossing the border. All these factor found very contributing to avoid vacnnination program, and no medical intervention and polio program be implemented in these areas, therefore still we have about 6 polio cases detected in the menionted areas. according to the WHO report 2015.

\section{Conclusion}

Polo drops are an approache in order to eradicate the polio virus which must be exisited, followed by the drops and can regularly been implemented to the children underfive, in addition the governments are responsible to do much for the improvement of the their population heatlh and have to refresh their commitment in this connection again and again.

Polio threathens the individual, families and as a whole the government to take strict act for the eradication of the polio and enhace the level of knowledge about the polio to understand the nature of the disease and alert the public to such badly physical damageing diseases. If case of some case detects any where in the country, while be in the secured or insecured places, as soon as the case should be reported to the Health facility for the post taking care and furthere counselling needed.

One of the major problem is the cross borader points and refugees, which can contribute the polio prevalence among the both nations in the bordering areas. all precautionary measure should be taken (information about polio, dissemination of brochure, radio stations, and any sound or print media is possibly applicable and can play positive role in awaring the public well be very benificails. 
DOI: $10.21522 /$ TIJPH.2013.05.04.Art050

ISSN: $2520-3134$

Its quite horrible that permannts physical inability have the biggest impact on the individual, family and governmental system, so unemployment is a big problem in the society, unproductivity and low income is also the major problem for the post polio clients. So all these contributing factors can be removed within forcing and pushing the govenment to provide the polio drops for each under five year of age within the each interval and regular bases and ensure the health of each individual to live healthy and happy to take part in a very active way in the society to run their lives by them self and free of polio problematic issue.

\section{References}

[1].CDC. Recommended childhood immunization schedule -- United States, 1999. MMWR 1999;48:12-6.

[2].Duffy J. The sanitarians: a history of public health. Urbana, Illinois: University of Illinois Press, 1990.

[3].Fenner F, Henderson DA, Arita I, Jezek Z, Ladnyi ID. Smallpox and its eradication. Geneva, Switzerland: World Health Organization, 1988.

[4].Plotkin SA, Orenstein WA. Vaccines. 3rd ed. Philadelphia, Pennsylvania: WB Saunders Co., 1999.

[5].US Department of Health, Education, and Welfare. Vital statistics -- special report, national summaries: reported incidence of selected notifiable diseases, United States, each division and state, 1920-50. Washington, DC: US Department of Health, Education, and Welfare, Public Health Service, National Office of Vital Statistics, 1953:37.

[6].US Department of Health, Education, and Welfare. Vital statistics rates in the United States, 1940-1960. Washington, DC: US Department of Health, Education, and Welfare, Public Health Service, National Center for Health Statistics, 1968. 